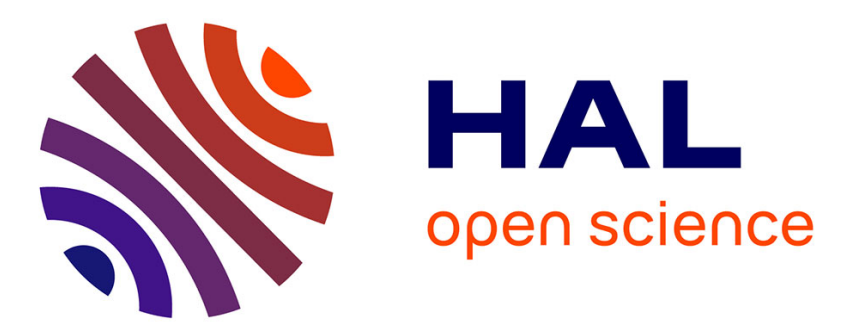

\title{
A CeVeFE DDFV scheme for discontinuous anisotropic permeability tensors
}

\author{
Yves Coudière, Florence Hubert, Gianmarco Manzini
}

\section{To cite this version:}

Yves Coudière, Florence Hubert, Gianmarco Manzini. A CeVeFE DDFV scheme for discontinuous anisotropic permeability tensors. Finite Volume for Complex Applications VI, Jun 2011, Praha, Czech Republic. pp.283-292. hal-00580540

\section{HAL Id: hal-00580540 \\ https://hal.science/hal-00580540}

Submitted on 28 Mar 2011

HAL is a multi-disciplinary open access archive for the deposit and dissemination of scientific research documents, whether they are published or not. The documents may come from teaching and research institutions in France or abroad, or from public or private research centers.
L'archive ouverte pluridisciplinaire HAL, est destinée au dépôt et à la diffusion de documents scientifiques de niveau recherche, publiés ou non, émanant des établissements d'enseignement et de recherche français ou étrangers, des laboratoires publics ou privés. 


\title{
A CeVeFE DDFV scheme for discontinuous anisotropic permeability tensors
}

\author{
Yves Coudière, Florence Hubert and Gianmarco Manzini
}

\begin{abstract}
In this work we derive a formulation for discontinuous diffusion tensor for the Discrete Duality Finite Volume (DDFV) framework that is exact for affine solutions. In fact, DDFV methods can naturally handle anisotropic or non-linear problems on general distorded meshes. Nonetheless, a special treatment is required when the diffusion tensor is discontinuous across an internal interfaces shared by two control volumes of the mesh. In such a case, two different gradients are considered in the two subdiamonds centered at that interface and the flux conservation is imposed through an auxiliary variable at the interface.
\end{abstract}

Key words: Finite volume schemes, Darcy flow

MSC2010: 65N08, 76S05

\section{Introduction}

In this proceeding we propose a Discrete Duality Finite Volume (DDFV) method that can handle discontinuous permeability coefficients. This method is a variant of the DDFV formulation proposed by Y. Coudière and F. Hubert in [6] to extend to three-dimensional (3D) problems the original two-dimensional finite volume schemes by F. Hermeline [11] and K. Domelevo and P. Omnès [9]. In the DDFV approach the diffusive flux is approximated using a piecewise constant approximation of the solution gradient over a set of edge-based cells called diamond cells. In the

Yves Coudière

Laboratoire Jean Leray, Nantes, FRANCE, e-mail: Yves . Coudiere@univ-nantes. fr

Florence Hubert

LATP, Université de Provence, Marseille, FRANCE, e-mail: fhubert@cmi • univ-mrs . fr

Gianmarco Manzini

IMATI and CESNA-IUSS, Pavia, ITALY, e-mail: gm.manzini@gmail.com 
two dimensional formulation, the gradient is approximated by a formula that requires the vertex values of the scalar solution. Following the DDFV approach, such vertex values are the solution of another finite volume method whose control volumes are built around the vertices. Therefore, the resulting scheme combines two distinct finite volume methods for the cell unknowns and the vertex unknowns on two overlapping meshes. Effectiveness and efficiency of such coupled finite volume formulation are documented in $[5,10]$.

Several generalizations of the two-dimensional DDFV formulation have been proposed in the literature; it is worth mentioning the works by F. Hermeline in [12], C. Pierre in $[13,8]$, and B. Andreianov and collaborators in $[3,4,2,1]$. Here, we consider the alternative construction proposed in [6], which uses two families of additional unknowns. In the first family, the unknowns are located at the vertices of the mesh and are the solution of a finite volume method whose control volumes are built around the vertices. In the second family, the unknowns are located at the centers of mesh edges and faces and are the solution of a finite volume method whose control volumes are built around such geometric objects. Therefore, the resulting scheme couples three distinct finite volume methods through a 3D gradient formula that generalizes the 2D one on a set of special cells, the so called diamond cells, built around edges and faces as will be discussed in the next sub-section.

The outline of the paper is as follows. In Section 2 we present a short review of the DDFV method. In Section 3 we present the numerical treatment that we propose for the case of discontinuous permeabilities. In Section 4 we offer final remarks and conclusions.

\section{The Discrete Duality Finite volume formulation}

\section{Meshes}

Given a general finite volume mesh $\mathscr{M}$ of the computational domain $\Omega$, composed of polyhedra, three additional polyhedral partitions of $\Omega$ are built, denoted by $\mathscr{N}$, $\mathscr{F} \mathscr{E}$ and $\mathscr{D}$, hereafter described.

We denote the control volumes of the initial mesh $\mathscr{M}$ by K or L. The set $\partial \mathscr{M}$ gathers the boundary faces, which we consider as degenerated control volumes, and we complete the initial mesh as $\overline{\mathscr{M}}=\mathscr{M} \cup \partial \mathscr{M}$. We associate a set of points $x_{\mathrm{K}} \in \mathrm{K}$ with the control volumes in $\overline{\mathscr{M}}$; specifically, in the current applications we use the arithmetic average of the vertex position vectors for each polyhedral cell. We denote the vertices, the edges, and the faces of mesh $\mathscr{M}$ by $x_{\mathrm{A}}, \mathrm{E}$ and F, respectively, and we define some additional points: the center of gravity $x_{\mathrm{F}}$ of each face $\mathrm{F}$ and the midpoint $x_{\mathrm{E}}$ of each edge $\mathrm{E}$. These points are ordered following the relation

$$
x_{\mathrm{A}} \prec x_{\mathrm{E}} \prec x_{\mathrm{F}} \prec x_{\mathrm{K}} \quad \text { which means that } \quad x_{\mathrm{A}} \subset \partial \mathrm{E}, \quad \mathrm{E} \subset \partial \mathrm{F}, \quad \mathrm{F} \subset \partial \mathrm{K} \text {. }
$$


The 3D gradient formula that we will introduce in the next subsection provides a piecewise constant approximation of the solution gradient on the mesh $\mathscr{D}$, which is the set of diamond cells D. To each one of the pairs "(edge, face)" (E,F) related by $x_{\mathrm{E}} \prec x_{\mathrm{F}}$ there corresponds a different diamond cell D that we define as follows. Cell D is the convex polyhedra with vertices $x_{\mathrm{A}}, x_{\mathrm{B}}, x_{\mathrm{E}}, x_{\mathrm{F}}, x_{\mathrm{K}}, x_{\mathrm{L}}$, where $x_{\mathrm{A}}$ and $x_{\mathrm{B}}$ denote the endpoints of $\mathrm{E}, \mathrm{K}$ and $\mathrm{L}$ the two cells sharing the common face F. Specifically, it holds that $\mathrm{D}=\operatorname{hull}\left(x_{\mathrm{A}}, x_{\mathrm{F}}, x_{\mathrm{B}}, x_{\mathrm{K}}\right) \cup \operatorname{hull}\left(x_{\mathrm{A}}, x_{\mathrm{F}}, x_{\mathrm{B}}, x_{\mathrm{L}}\right)$. We associate with each diamond cell D the point $x_{\mathrm{D}}=\frac{1}{2}\left(x_{\mathrm{E}}+x_{\mathrm{F}}\right) \in \mathrm{D}$.

We partition each diamond cell into eight tetrahedra sharing $x_{\mathrm{D}}$ as common vertex and having the remaining three vertices chosen within the pairs $\left(x_{\mathrm{A}}, x_{\mathrm{B}}\right),\left(x_{\mathrm{E}}, x_{\mathrm{F}}\right)$ and $\left(x_{\mathrm{K}}, x_{\mathrm{L}}\right)$, respectively. Formally, we denote the eight possible combinations by

$$
\mathrm{D}=\operatorname{hull}\left(x_{\mathrm{D}},\left(\begin{array}{c}
x_{\mathrm{A}} \\
x_{\mathrm{B}}
\end{array}\right),\left(\begin{array}{c}
x_{\mathrm{E}} \\
x_{\mathrm{F}}
\end{array}\right),\left(\begin{array}{c}
x_{\mathrm{K}} \\
x_{\mathrm{L}}
\end{array}\right)\right), \quad \text { with } \quad\left(\begin{array}{c}
x_{\mathrm{A}} \\
x_{\mathrm{B}}
\end{array}\right) \prec x_{\mathrm{E}} \prec x_{\mathrm{F}} \prec\left(\begin{array}{c}
x_{\mathrm{K}} \\
x_{\mathrm{L}}
\end{array}\right) .
$$

We assume the six vertices $x_{\mathrm{K}}, x_{\mathrm{L}}, x_{\mathrm{A}}, x_{\mathrm{B}}$ and $x_{\mathrm{E}}, x_{\mathrm{F}}$ of the diamond cell $\mathrm{D}(\mathrm{E}, \mathrm{F})$ to be ordered in such a way that $\Delta_{\mathrm{EF}}:=\operatorname{det}\left(x_{\mathrm{B}}-x_{\mathrm{A}}, x_{\mathrm{F}}-x_{\mathrm{E}}, x_{\mathrm{L}}-x_{\mathrm{K}}\right)>0$. Thus, the measure of D is $|\mathrm{D}|=\frac{1}{6} \Delta_{\mathrm{EF}}$.

We denote the control volume associated with a vertex $x_{\mathrm{A}}$ of the mesh by A. This control volume is built by gathering the contributions (i.e., sub-tetraedra) of the diamond cells that share vertex $x_{\mathrm{A}}$ as:

$$
\mathrm{A}=\underset{\mathrm{D} \in \mathrm{D}_{\mathrm{A}}}{\cup} \operatorname{hull}\left(x_{\mathrm{D}}, x_{\mathrm{A}},\left(\begin{array}{c}
x_{\mathrm{E}} \\
x_{\mathrm{F}}
\end{array}\right),\left(\begin{array}{c}
x_{\mathrm{K}} \\
x_{\mathrm{L}}
\end{array}\right)\right),
$$

where $\mathrm{D}_{\mathrm{A}}=\left\{\mathrm{D} \in \mathscr{D}\right.$, such that $\left.x_{\mathrm{A}} \prec x_{\mathrm{E}} \prec x_{\mathrm{F}}\right\}$ for $x_{\mathrm{A}}$ fixed. The resulting finite volume partition of $\Omega$, denoted by $\bar{N}$, forms the vertex mesh. The vertex mesh is split into interior and boundary controls volumes, respectively denoted by $\mathscr{N}$ and $\partial \mathscr{N}$; formally, it holds that $\overline{\mathscr{N}}=\mathscr{N} \cup \partial \mathscr{N}$.

Similarly, we associate a control volume denoted either by F or by E, with the point $x_{\mathrm{F}}$ (face center) or the point $x_{\mathrm{E}}$ (edge midpoint) in accordance with the following formula:

$$
\mathrm{E}=\underset{\mathrm{D} \in \mathrm{D}_{\mathrm{E}}}{\cup} \operatorname{hull}\left(x_{\mathrm{D}},\left(\begin{array}{c}
x_{\mathrm{A}} \\
x_{\mathrm{B}}
\end{array}\right), x_{\mathrm{E}},\left(\begin{array}{c}
x_{\mathrm{K}} \\
x_{\mathrm{L}}
\end{array}\right)\right), \quad \mathrm{F}=\underset{\mathrm{D} \in \mathrm{D}_{\mathrm{F}}}{\cup} \operatorname{hull}\left(x_{\mathrm{D}},\left(\begin{array}{c}
x_{\mathrm{A}} \\
x_{\mathrm{B}}
\end{array}\right), x_{\mathrm{F}},\left(\begin{array}{c}
x_{\mathrm{K}} \\
x_{\mathrm{L}}
\end{array}\right)\right),
$$

where $\mathrm{D}_{\mathrm{E}}=\left\{\mathrm{D} \in \mathscr{D}\right.$, with $\left.x_{\mathrm{E}} \prec x_{\mathrm{F}}\right\}$ with $x_{\mathrm{E}}$ fixed and $\mathrm{D}_{\mathrm{F}}=\left\{\mathrm{D} \in \mathscr{D}\right.$, with $\left.x_{\mathrm{E}} \prec x_{\mathrm{F}}\right\}$ with $x_{\mathrm{F}}$ fixed. The resulting finite volume partition of $\Omega$, denoted by $\overline{\mathscr{F} \mathscr{E}}$, is the face-edge mesh. This partition contains both control volumes associated with the faces and the edges of the initial mesh and is split into the interior and boundary controls volumes, respectively denoted by $\mathscr{F} \mathscr{E}$ and $\partial \mathscr{F} \mathscr{E}$; formally, it holds that $\overline{\mathscr{F} \mathscr{E}}=\mathscr{F} \mathscr{E} \cup \partial \mathscr{F} \mathscr{E}$. 


\section{The 3D “Cell-Vertex-Face/Edge" DDFV Scheme}

We say that $u^{\mathscr{T}}=\left(u^{\mathscr{M}}, u^{\mathscr{N}}, u^{\mathscr{F} \mathscr{E}}\right)$ is a discrete function on $\Omega$ whenever its three components are piecewise constant functions on the meshes $\mathscr{M}, \mathscr{N}$ and $\mathscr{F} \mathscr{E}$, respectively, and take the form

$$
u^{\mathscr{M}}=\sum_{\mathrm{K} \in \mathscr{M}} u_{\mathrm{K}} \chi_{\mathrm{K}}, \quad u^{\mathscr{N}}=\sum_{A \in \mathscr{N}} u_{\mathrm{A}} \chi_{A}, \quad u^{\mathscr{F} \mathscr{E}}=\sum_{\mathrm{F} \in \mathscr{F}} u_{\mathrm{F}} \chi_{\mathrm{F}}+\sum_{\mathrm{E} \in \mathscr{E}} u_{\mathrm{E}} \chi_{\mathrm{E}}
$$

Let $X$ denote the set of the degrees of freedom of the form

$$
u^{\mathscr{T}}=\left(\left(u_{\mathrm{K}}\right)_{K \in \mathscr{M}},\left(u_{\mathrm{A}}\right)_{A \in \mathscr{N}},\left(u_{\mathrm{E}}\right)_{E \in \mathscr{E}},\left(u_{\mathrm{F}}\right)_{F \in \mathscr{F}}\right)
$$

In order to take into account the Dirichlet boundary conditions, this set is supplemented by the boundary data

$$
\delta u^{\mathscr{T}}=\left(\left(u_{\mathrm{K}}\right)_{x_{\mathrm{K}} \in \partial \mathscr{M}},\left(u_{\mathrm{A}}\right)_{x_{\mathrm{A}} \in \partial \mathscr{N}},\left(u_{\mathrm{E}}\right)_{x_{\mathrm{E}} \in \partial \mathscr{F} \mathscr{E}},\left(u_{\mathrm{F}}\right)_{x_{\mathrm{F}} \in \partial \mathscr{F} \mathscr{E}}\right)
$$

which form the set $\partial X$. We will search the numerical approximation to the scalar solution field $u$ in the product set $\left(u^{\mathscr{T}}, \delta u^{\mathscr{T}}\right) \in X \times \partial X$. Note that $X, \partial X$, and $X \times \partial X$ can be given the algebraic structure of a linear space after introducing (in the obvious way) the addition of two elements of the set and the multiplication of an element of the set by a real number.

The gradient of the discrete unknown $u^{\mathscr{T}}$, denoted by $\nabla^{\mathscr{T}} u^{\mathscr{T}}$, is a constant vector field on each diamond cell and is identified with a piecewise constant vector field on mesh $\mathscr{D}$. It depends on the boundary data $\delta u^{\mathscr{T}}$ and can be written as $\nabla_{\delta u}^{\mathscr{T}} u^{\mathscr{T}}=$ $\sum_{\mathrm{D} \in \mathscr{D}} \nabla_{\delta u}^{\mathrm{D}} u^{\mathscr{T}} \chi_{\mathrm{D}}$ where

$$
\nabla_{\delta u}^{\mathrm{D}} u^{\mathscr{T}}=\frac{1}{3|\mathrm{D}|}\left(\left(u_{\mathrm{L}}-u_{\mathrm{K}}\right) N_{\mathrm{KL}}+\left(u_{\mathrm{B}}-u_{\mathrm{A}}\right) N_{\mathrm{AB}}+\left(u_{\mathrm{F}}-u_{\mathrm{E}}\right) N_{\mathrm{EF}}\right) .
$$

for any $\mathrm{D} \in \mathscr{D}$ and with the vectors $N_{\mathrm{KL}}=\frac{1}{2}\left(x_{\mathrm{B}}-x_{\mathrm{A}}\right) \times\left(x_{\mathrm{F}}-x_{\mathrm{E}}\right), N_{\mathrm{AB}}=\frac{1}{2}\left(x_{\mathrm{F}}-\right.$ $\left.x_{\mathrm{E}}\right) \times\left(x_{\mathrm{L}}-x_{\mathrm{K}}\right)$ and $N_{\mathrm{EF}}=\frac{1}{2}\left(x_{\mathrm{L}}-x_{\mathrm{K}}\right) \times\left(x_{\mathrm{B}}-x_{\mathrm{A}}\right)$. This procedure defines a gradient operator, denoted by $\nabla_{\delta u}^{\mathscr{T}}$, mapping the discrete space $X$ onto the space of the discrete vector fields $\nabla^{\mathscr{T}} u^{\mathscr{T}}$, which we conveniently denote by $\mathbf{Q}$.

Using the gradient formula we define the flux through each interface of the control volumes of the three meshes $\mathscr{M}, \mathscr{N}$ and $\mathscr{F} \mathscr{E}$. The three finite volume schemes are written by using a discrete divergence operator that maps each vector field in $\mathbf{Q}$ to a triple of scalar functions in $X$. Formally, we introduce the operator

$$
\operatorname{div}^{\mathscr{T}}: \xi=\left(\xi_{\mathrm{D}}\right)_{\mathrm{D} \in \mathscr{D}} \in \mathbf{Q} \mapsto\left(\operatorname{div}^{\mathscr{M}} \xi, \operatorname{div}^{\mathscr{N}} \xi, \operatorname{div}^{\mathscr{F} \mathscr{E}} \xi\right) \in X
$$

where $\operatorname{div}^{\mathscr{M}} \xi=\left(\operatorname{div}_{\mathrm{K}} \xi\right)_{\mathrm{K}}, \operatorname{div}^{\mathscr{N}} \xi=\left(\operatorname{div}_{\mathrm{A}} \xi\right)_{\mathrm{A}}$ and $\operatorname{div}^{\mathscr{F} \mathscr{E}} \xi=\left\{\left(\operatorname{div}_{\mathrm{E}} \xi\right)_{\mathrm{E}},\left(\operatorname{div}_{\mathrm{F}} \xi\right)_{\mathrm{F}}\right\}$ are given by 


$$
\begin{aligned}
|\mathrm{K}| \operatorname{div}_{\mathrm{K}} \xi & =\sum_{\mathrm{D} \in \mathrm{D}_{\mathrm{K}}} \xi_{\mathrm{D}} \cdot N_{\mathrm{KL}}, \quad|\mathrm{A}| \operatorname{div}_{\mathrm{A}} \xi=\sum_{\mathrm{D} \in \mathrm{D}_{\mathrm{A}}} \xi_{\mathrm{D}} \cdot N_{\mathrm{AB}}, \\
|\mathrm{E}| \operatorname{div}_{\mathrm{E}} \xi & =\sum_{\mathrm{D} \in \mathrm{D}_{\mathrm{E}}} \xi_{\mathrm{D}} \cdot N_{\mathrm{EF}}, \quad|\mathrm{F}| \operatorname{div}_{\mathrm{F}} \xi=\sum_{\mathrm{D} \in \mathrm{D}_{\mathrm{F}}} \xi_{\mathrm{D}} \cdot\left(-N_{\mathrm{EF}}\right) .
\end{aligned}
$$

In the previous statements, the symbols $\mathrm{D}_{\mathrm{K}}, \mathrm{D}_{\mathrm{A}}, \mathrm{D}_{\mathrm{E}}, \mathrm{D}_{\mathrm{F}}$ refer to the diamond cells which overlap the cells labeled by the corresponding subscripted indices $\mathrm{K}, \mathrm{A}, \mathrm{E}$, and $\mathrm{L}$.

Since each of the $\operatorname{div}_{\mathrm{C}} \xi$ approximates $\frac{1}{|\mathrm{C}|} \int_{\mathrm{C}} \operatorname{div} \xi$ (for C $=\mathrm{K}, \mathrm{A}, \mathrm{E}, \mathrm{F}$ ), the right hand side of the discrete problem is given by the piecewise constant projection of the function $f$ onto the space $X, \pi^{\mathscr{T}} f=\left\{\left(f_{\mathrm{K}}\right)_{\mathrm{K} \in \mathscr{M}},\left(f_{\mathrm{A}}\right)_{\mathrm{A} \in \mathscr{N}},\left(f_{\mathrm{E}}, f_{\mathrm{F}}\right)_{\mathrm{E} \in \mathscr{E}, \mathrm{F} \in \mathscr{F}}\right\}$ with $f_{\mathrm{C}}=\frac{1}{|\mathrm{C}|} \int_{\mathrm{C}} f(x) d x$ for any cell $\mathrm{C}=\mathrm{K} \in \mathscr{M}$ or $\mathrm{A} \in \mathscr{N}$ or $\mathrm{F}$ or $\mathrm{E} \in \mathscr{F} \mathscr{E}$.

Finally, the DDFV scheme reads as

$$
-\operatorname{div}^{\mathscr{T}}\left(\mathbf{K}_{\mathrm{D}} \nabla_{\delta u}^{\mathrm{D}} u^{\mathscr{T}}\right)=\pi^{\mathscr{T}} f
$$

where $\mathbf{K}_{\mathrm{D}}=\frac{1}{|\mathrm{D}|} \int_{\mathrm{D}} \mathbf{K}(x) d x$ is defined piecewise on the diamond cells. The scheme in (4) originates a symmetric and positive-definite linear system of equations (see [6] for a thourough discussion of the other properties). Assembling the matrix of the system amounts to gathering the local contributions of the discrete gradient associated to each diamond cell. These contributions are explicitly taken into account by the local Gram matrix

$$
\mathbb{K}_{\mathrm{D}}=\left(\begin{array}{lll}
\mathbf{K}_{\mathrm{D}} N_{\mathrm{KL}} \cdot N_{\mathrm{KL}} & \mathbf{K}_{\mathrm{D}} N_{\mathrm{KL}} \cdot N_{\mathrm{AB}} & \mathbf{K}_{\mathrm{D}} N_{\mathrm{KL}} \cdot N_{\mathrm{EF}} \\
\mathbf{K}_{\mathrm{D}} N_{\mathrm{AB}} \cdot N_{\mathrm{KL}} & \mathbf{K}_{\mathrm{D}} N_{\mathrm{AB}} \cdot N_{\mathrm{AB}} & \mathbf{K}_{\mathrm{D}} N_{\mathrm{AB}} \cdot N_{\mathrm{EF}} \\
\mathbf{K}_{\mathrm{D}} N_{\mathrm{EF}} \cdot N_{\mathrm{KL}} & \mathbf{K}_{\mathrm{D}} N_{\mathrm{EF}} \cdot N_{\mathrm{AB}} & \mathbf{K}_{\mathrm{D}} N_{\mathrm{EF}} \cdot N_{\mathrm{EF}}
\end{array}\right)
$$

The right hand side in (4) is split similarly in elementary contributions on the eight tetrahedra that compose the diamond cells D.

\section{Treatment of discontinuous permeability tensors}

The case of a discontinuous permeability tensor in the DDFV framework deserves a special treatment that we discuss in this subsection. Let us suppose that the permeability tensor is discontinuous across the interfaces of the control volumes of mesh $\mathscr{M}$. We decompose each diamond cell into two sub-diamonds $\mathrm{D}_{\mathrm{K}}$ and $\mathrm{D}_{\mathrm{L}}$, i.e., $\mathrm{D}=\mathrm{D}_{\mathrm{K}} \cup \mathrm{D}_{\mathrm{L}}$, where $\mathrm{D}_{\mathrm{K}}$ is the union of the four tetrahedra with vertices $x_{\mathrm{D}}, x_{\mathrm{K}}$, the third vertex being $x_{\mathrm{A}}$ or $x_{\mathrm{B}}$, and the fourth vertex being $x_{\mathrm{E}}$ or $x_{\mathrm{F}}$.

Then, we introduce an additional degree of freedom at $x_{\mathrm{D}}$, the center of the diamond cell, and we write a gradient formula that is exact for affine functions on the two sub-diamonds. We obtain the two following formulas 


$$
\begin{aligned}
& \nabla_{\mathrm{K}}^{\mathscr{T}} u^{\mathscr{T}}=\frac{1}{3\left|\mathrm{D}_{\mathrm{K}}\right|}\left(\left(u_{\mathrm{D}}-u_{\mathrm{K}}\right) N_{\mathrm{KL}}+\left(u_{\mathrm{B}}-u_{\mathrm{A}}\right) N_{\mathrm{AB}}^{\mathrm{K}}+\left(u_{\mathrm{F}}-u_{\mathrm{E}}\right) N_{\mathrm{EF}}^{\mathrm{K}}\right) \\
& \nabla_{\mathrm{L}}^{\mathscr{T}} u^{\mathscr{T}}=\frac{1}{3\left|\mathrm{D}_{\mathrm{L}}\right|}\left(\left(u_{\mathrm{L}}-u_{\mathrm{D}}\right) N_{\mathrm{KL}}+\left(u_{\mathrm{B}}-u_{\mathrm{A}}\right) N_{\mathrm{AB}}^{\mathrm{L}}+\left(u_{\mathrm{F}}-u_{\mathrm{E}}\right) N_{\mathrm{EF}}^{\mathrm{L}}\right)
\end{aligned}
$$

using the geometric vectors $N_{\mathrm{AB}}^{\mathrm{K}}=\frac{1}{2}\left(x_{\mathrm{F}}-x_{\mathrm{E}}\right) \times\left(x_{\mathrm{D}}-x_{\mathrm{K}}\right), N_{\mathrm{AB}}^{\mathrm{L}}=\frac{1}{2}\left(x_{\mathrm{F}}-x_{\mathrm{E}}\right) \times\left(x_{\mathrm{L}}-\right.$ $\left.x_{\mathrm{D}}\right), N_{\mathrm{EF}}^{\mathrm{K}}=\frac{1}{2}\left(x_{\mathrm{D}}-x_{\mathrm{K}}\right) \times\left(x_{\mathrm{B}}-x_{\mathrm{A}}\right), N_{\mathrm{EF}}^{\mathrm{L}}=\frac{1}{2}\left(x_{\mathrm{L}}-x_{\mathrm{D}}\right) \times\left(x_{\mathrm{B}}-x_{\mathrm{A}}\right)$, and introducing the two volume factors $\left|\mathrm{D}_{\mathrm{K}}\right|=\frac{1}{6} \operatorname{det}\left(x_{\mathrm{B}}-x_{\mathrm{A}}, x_{\mathrm{F}}-x_{\mathrm{E}}, x_{\mathrm{D}}-x_{\mathrm{K}}\right)$ and $\left|\mathrm{D}_{\mathrm{L}}\right|=\frac{1}{6} \operatorname{det}\left(x_{\mathrm{B}}-\right.$ $\left.x_{\mathrm{A}}, x_{\mathrm{F}}-x_{\mathrm{E}}, x_{\mathrm{L}}-x_{\mathrm{D}}\right)$. Also, we remark that $|\mathrm{D}|=\left|\mathrm{D}_{\mathrm{K}}\right|+\left|\mathrm{D}_{\mathrm{L}}\right|, N_{\mathrm{AB}}=N_{\mathrm{AB}}^{\mathrm{K}}+N_{\mathrm{AB}}^{\mathrm{L}} N_{\mathrm{EF}}=$ $N_{\mathrm{EF}}^{\mathrm{K}}+N_{\mathrm{EF}}^{\mathrm{L}}$ and it holds that $\left|\mathrm{D}_{\mathrm{K}}\right| N_{\mathrm{AB}}^{\mathrm{L}}-\left|\mathrm{D}_{\mathrm{L}}\right| N_{\mathrm{AB}}^{\mathrm{K}}=\left|\mathrm{D}_{\mathrm{K}}\right| N_{\mathrm{AB}}-|\mathrm{D}| N_{\mathrm{AB}}^{\mathrm{L}}$.

Let $\mathbf{K}_{\mathrm{D}_{\mathrm{K}}}=\frac{1}{\left|\mathrm{D}_{\mathrm{K}}\right|} \int_{\mathrm{D}_{\mathrm{K}}} \mathbf{K}(x) d x$ and $\mathbf{K}_{\mathrm{D}_{\mathrm{L}}}=\frac{1}{\left|\mathrm{D}_{\mathrm{L}}\right|} \int_{\mathrm{D}_{\mathrm{L}}} \mathbf{K}(x) d x$ be the constant approximation of the diffusion tensor on the two sub-diamonds $\mathrm{D}_{K}$ and $\mathrm{D}_{L}$. We determine the additional unknown $u_{\mathrm{D}}$ in terms of the other local degrees of freedom $u_{\mathrm{K}}, u_{\mathrm{L}}, u_{\mathrm{A}}$, $u_{\mathrm{B}}, u_{\mathrm{E}}$ and $u_{\mathrm{F}}$ by imposing that

$$
\mathbf{K}_{\mathrm{D}_{\mathrm{K}}} \nabla_{\mathrm{K}}^{\mathscr{T}} u^{\mathscr{T}} \cdot N_{\mathrm{KL}}=\mathbf{K}_{\mathrm{D}_{\mathrm{L}}} \nabla_{\mathrm{L}}^{\mathscr{T}} u^{\mathscr{T}} \cdot N_{\mathrm{KL}}
$$

which is the flux conservation through the common face $\mathrm{D}_{K} \mid \mathrm{D}_{L}$. Moreover, let us introduce the following geometric factors that also depend on the permeability coefficients:

$$
\begin{aligned}
& \beta_{K L}=+\left|\mathrm{D}_{\mathrm{L}}\right| \mathbf{K}_{\mathrm{D}_{\mathrm{K}}} N_{\mathrm{KL}} \cdot N_{\mathrm{KL}}+\left|\mathrm{D}_{\mathrm{K}}\right| \mathbf{K}_{\mathrm{D}_{\mathrm{L}}} N_{\mathrm{KL}} \cdot N_{\mathrm{KL}} \\
& \beta_{A B}=-\left|\mathrm{D}_{\mathrm{L}}\right| \mathbf{K}_{\mathrm{D}_{\mathrm{K}}} N_{\mathrm{AB}}^{\mathrm{K}} \cdot N_{\mathrm{KL}}+\left|\mathrm{D}_{\mathrm{K}}\right| \mathbf{K}_{\mathrm{D}_{\mathrm{L}}} N_{\mathrm{AB}}^{\mathrm{L}} \cdot N_{\mathrm{KL}} \\
& \beta_{E F}=-\left|\mathrm{D}_{\mathrm{L}}\right| \mathbf{K}_{\mathrm{D}_{\mathrm{K}}} N_{\mathrm{EF}}^{\mathrm{K}} \cdot N_{\mathrm{KL}}+\left|\mathrm{D}_{\mathrm{K}}\right| \mathbf{K}_{\mathrm{D}_{\mathrm{L}}} N_{\mathrm{EF}}^{\mathrm{L}} \cdot N_{\mathrm{KL}}
\end{aligned}
$$

A straightforward calculation yields the formula for $u_{\mathrm{D}}$

$u_{\mathrm{D}}=\frac{\left|\mathrm{D}_{\mathrm{L}}\right| \mathbf{K}_{\mathrm{D}_{\mathrm{K}}} N_{\mathrm{KL}} \cdot N_{\mathrm{KL}}}{\beta_{K L}} u_{\mathrm{K}}+\frac{\left|\mathrm{D}_{\mathrm{K}}\right| \mathbf{K}_{\mathrm{D}_{\mathrm{L}}} N_{\mathrm{KL}} \cdot N_{\mathrm{KL}}}{\beta_{K L}} u_{\mathrm{L}}+\frac{\beta_{A B}}{\beta_{K L}}\left(u_{\mathrm{B}}-u_{\mathrm{A}}\right)+\frac{\beta_{E F}}{\beta_{K L}}\left(u_{\mathrm{F}}-u_{\mathrm{E}}\right)$,

and the formulas for the numerical gradients:

$$
\begin{aligned}
3 \nabla_{\mathrm{K}}^{\mathscr{T}} u^{\mathscr{T}}= & \frac{\mathbf{K}_{\mathrm{D}_{\mathrm{L}}} N_{\mathrm{KL}} \cdot N_{\mathrm{KL}}}{\beta_{K L}} N_{\mathrm{KL}}\left(u_{\mathrm{L}}-u_{\mathrm{K}}\right)+\left(\frac{\beta_{A B}}{\left|\mathrm{D}_{\mathrm{K}}\right| \beta_{K L}} N_{\mathrm{KL}}+\frac{1}{\left|\mathrm{D}_{\mathrm{K}}\right|} N_{\mathrm{AB}}^{\mathrm{K}}\right)\left(u_{\mathrm{B}}-u_{\mathrm{A}}\right) \\
& +\left(\frac{\beta_{E F}}{\left|\mathrm{D}_{\mathrm{K}}\right| \beta_{K L}} N_{\mathrm{KL}}+\frac{1}{\left|\mathrm{D}_{\mathrm{K}}\right|} N_{\mathrm{EF}}^{\mathrm{K}}\right)\left(u_{\mathrm{F}}-u_{\mathrm{E}}\right), \\
3 \nabla_{\mathrm{L}}^{\mathscr{T}} u^{\mathscr{T}}= & \frac{\mathbf{K}_{\mathrm{D}_{\mathrm{K}}} N_{\mathrm{KL}} \cdot N_{\mathrm{KL}}}{\beta_{K L}} N_{\mathrm{KL}}\left(u_{\mathrm{L}}-u_{\mathrm{K}}\right)+\left(\frac{\beta_{A B}}{\left|\mathrm{D}_{\mathrm{L}}\right| \beta_{K L}} N_{\mathrm{KL}}+\frac{1}{\left|\mathrm{D}_{\mathrm{L}}\right|} N_{\mathrm{AB}}^{\mathrm{L}}\right)\left(u_{\mathrm{B}}-u_{\mathrm{A}}\right) \\
& +\left(\frac{\beta_{E F}}{\left|\mathrm{D}_{\mathrm{L}}\right| \beta_{K L}} N_{\mathrm{KL}}+\frac{1}{\left|\mathrm{D}_{\mathrm{L}}\right|} N_{\mathrm{EF}}^{\mathrm{L}}\right)\left(u_{\mathrm{F}}-u_{\mathrm{E}}\right) .
\end{aligned}
$$

Finally, we define the divergence operator for a discrete vector field which is piecewise constant on $\mathrm{D}_{K} \cap \mathrm{D}_{L}$ and may be discontinuous across $\mathrm{D}_{K} \mid \mathrm{D}_{L}$ as 


$$
\begin{aligned}
|\mathrm{K}| \operatorname{div}_{\mathrm{K}} \xi^{\mathscr{D}} & =\sum_{\mathrm{D} \mid \mathrm{K}} \xi_{\mathrm{D}_{\mathrm{K}}} \cdot N_{\mathrm{KL}}=\sum_{\mathrm{D} \mid \mathrm{K}} \xi_{\mathrm{D}_{\mathrm{L}}} \cdot N_{\mathrm{KL}}=\sum_{\mathrm{D} \mid \mathrm{K}}\left(\frac{\left|\mathrm{D}_{\mathrm{K}}\right|}{|\mathrm{D}|} \xi_{\mathrm{D}_{\mathrm{K}}}+\frac{\left|\mathrm{D}_{\mathrm{L}}\right|}{|\mathrm{D}|} \xi_{\mathrm{D}_{\mathrm{L}}}\right) \cdot N_{\mathrm{KL}} \\
|\mathrm{A}| \operatorname{div}_{\mathrm{A}} \xi^{\mathscr{D}} & =\sum_{\mathrm{D} \mid \mathrm{A}}\left(\xi_{\mathrm{D}_{\mathrm{K}}} \cdot N_{\mathrm{AB}}^{\mathrm{K}}+\xi_{\mathrm{D}_{\mathrm{L}}} \cdot N_{\mathrm{AB}}^{\mathrm{L}}\right) \\
|\mathrm{E}| \operatorname{div}_{\mathrm{E}} \xi^{\mathscr{D}} & =\sum_{\mathrm{D} \mid \mathrm{E}}\left(\xi_{\mathrm{D}_{\mathrm{K}}} \cdot N_{\mathrm{EF}}^{\mathrm{K}}+\xi_{\mathrm{D}_{\mathrm{L}}} \cdot N_{\mathrm{EF}}^{\mathrm{L}}\right) \\
|\mathrm{F}| \operatorname{div}_{\mathrm{F}} \xi^{\mathscr{D}} & =\sum_{\mathrm{D} \mid \mathrm{D}_{\mathrm{F}}}\left(\xi_{\mathrm{D}_{\mathrm{K}}} \cdot\left(-N_{\mathrm{EF}}^{\mathrm{K}}\right)-\xi_{\mathrm{D}_{\mathrm{L}}} \cdot\left(-N_{\mathrm{EF}}^{\mathrm{L}}\right)\right) .
\end{aligned}
$$

The DDFV method for the discontinuous case follows by using (5)-(8) with the approximate permeability tensors $\mathbf{K}_{\mathrm{D}_{\mathrm{K}}}$ and $\mathbf{K}_{\mathrm{D}_{\mathrm{L}}}$ instead of (2)-(3) in the scheme formulation (4). Let $\xi^{\mathscr{D}}=\mathbf{K}^{\mathscr{D}} \nabla^{\mathscr{T}} u^{\mathscr{T}}$ and evaluate the quantities:

$$
\begin{aligned}
&\left(\frac{\left|\mathrm{D}_{\mathrm{K}}\right|}{|\mathrm{D}|} \xi_{\mathrm{D}_{\mathrm{K}}}+\frac{\left|\mathrm{D}_{\mathrm{L}}\right|}{|\mathrm{D}|} \xi_{\mathrm{D}_{\mathrm{L}}}\right) \cdot N_{\mathrm{KL}}=\alpha_{\mathrm{KL} \cdot \mathrm{KL}}\left(u_{\mathrm{L}}-u_{\mathrm{K}}\right)+\alpha_{\mathrm{KL} \cdot \mathrm{AB}}\left(u_{\mathrm{B}}-u_{\mathrm{A}}\right)+\alpha_{\mathrm{KL} \cdot \mathrm{EF}}\left(u_{\mathrm{F}}-u_{\mathrm{E}}\right) \\
& \xi_{\mathrm{D}_{\mathrm{K}}} \cdot N_{\mathrm{AB}}^{\mathrm{K}}+\xi_{\mathrm{D}_{\mathrm{L}}} \cdot N_{\mathrm{AB}}^{\mathrm{L}}=\alpha_{\mathrm{AB} \cdot \mathrm{KL}}\left(u_{\mathrm{L}}-u_{\mathrm{K}}\right)+\alpha_{\mathrm{AB} \cdot \mathrm{AB}}\left(u_{\mathrm{B}}-u_{\mathrm{A}}\right)+\alpha_{\mathrm{AB} \cdot \mathrm{EF}}\left(u_{\mathrm{F}}-u_{\mathrm{E}}\right) \\
& \xi_{\mathrm{D}_{\mathrm{K}}} \cdot N_{\mathrm{EF}}^{\mathrm{K}}+\xi_{\mathrm{D}_{\mathrm{L}}} \cdot N_{\mathrm{EF}}^{\mathrm{L}}=\alpha_{\mathrm{EF} \cdot \mathrm{KL}}\left(u_{\mathrm{L}}-u_{\mathrm{K}}\right)+\alpha_{\mathrm{EF} \cdot \mathrm{AB}}\left(u_{\mathrm{B}}-u_{\mathrm{A}}\right)+\alpha_{\mathrm{EF} \cdot \mathrm{EF}}\left(u_{\mathrm{F}}-u_{\mathrm{E}}\right)
\end{aligned}
$$

using the entries of the coefficient matrix

$$
\mathbf{K}_{\mathrm{D}}^{n e w}=\left(\begin{array}{ccc}
\alpha_{\mathrm{KL} \cdot \mathrm{KL}} & \alpha_{\mathrm{KL} \cdot \mathrm{AB}} & \alpha_{\mathrm{KL} \cdot \mathrm{EF}} \\
\alpha_{\mathrm{AB} \cdot \mathrm{KL}} & \alpha_{\mathrm{AB} \cdot \mathrm{AB}} & \alpha_{\mathrm{AB} \cdot \mathrm{EF}} \\
\alpha_{\mathrm{EF} \cdot \mathrm{KL}} & \alpha_{\mathrm{EF} \cdot \mathrm{AB}} & \alpha_{\mathrm{EF} \cdot \mathrm{EF}}
\end{array}\right) .
$$

Since $\mathbf{K}_{\mathrm{D}}^{\text {new }}$ is a $3 \times 3$ symmetric elements we have only six independent entries, which after a straightforward calculations are given by:

$$
\begin{aligned}
& \alpha_{\mathrm{KL} \cdot \mathrm{KL}}=\frac{1}{3} \frac{\mathbf{K}_{\mathrm{D}_{\mathrm{K}}} N_{\mathrm{KL}} \cdot N_{\mathrm{KL}} \mathbf{K}_{\mathrm{D}_{\mathrm{L}}} N_{\mathrm{KL}} \cdot N_{\mathrm{KL}}}{\beta_{K L}}, \\
& \alpha_{\mathrm{KL} \cdot \mathrm{AB}}=\frac{\mathbf{K}_{\mathrm{D}_{\mathrm{K}}} N_{\mathrm{KL}} \cdot N_{\mathrm{AB}}^{\mathrm{K}} \mathbf{K}_{\mathrm{D}_{\mathrm{L}}} N_{\mathrm{KL}} \cdot N_{\mathrm{KL}}+\mathbf{K}_{\mathrm{D}_{\mathrm{L}}} N_{\mathrm{KL}} \cdot N_{\mathrm{AB}}^{\mathrm{L}} \mathbf{K}_{\mathrm{D}_{\mathrm{K}}} N_{\mathrm{KL}} \cdot N_{\mathrm{KL}}}{\beta_{K L}}, \\
& \alpha_{\mathrm{KL} \cdot \mathrm{EF}}=\frac{1}{3} \frac{\mathbf{K}_{\mathrm{D}_{\mathrm{K}}} N_{\mathrm{KL}} \cdot N_{\mathrm{EF}}^{\mathrm{K}} \mathbf{K}_{\mathrm{D}_{\mathrm{L}}} N_{\mathrm{KL}} \cdot N_{\mathrm{KL}}+\mathbf{K}_{\mathrm{D}_{\mathrm{L}}} N_{\mathrm{KL}} \cdot N_{\mathrm{EF}}^{\mathrm{L}} \mathbf{K}_{\mathrm{D}_{\mathrm{K}}} N_{\mathrm{KL}} \cdot N_{\mathrm{KL}}}{\beta_{K L}}, \\
& \alpha_{\mathrm{AB} \cdot \mathrm{AB}}=\frac{1}{3}\left(-\frac{\beta_{A B}^{2}}{\left|\mathrm{D}_{\mathrm{K}}\right|\left|\mathrm{D}_{\mathrm{L}}\right| \beta_{K L}}+\frac{1}{\left|\mathrm{D}_{\mathrm{K}}\right|} \mathbf{K}_{\mathrm{D}_{\mathrm{K}}} N_{\mathrm{AB}}^{\mathrm{K}} \cdot N_{\mathrm{AB}}^{\mathrm{K}}+\frac{1}{\left|\mathrm{D}_{\mathrm{L}}\right|} \mathbf{K}_{\mathrm{D}_{\mathrm{L}}} N_{\mathrm{AB}}^{\mathrm{L}} \cdot N_{\mathrm{AB}}^{\mathrm{L}}\right), \\
& \alpha_{\mathrm{EF} \cdot \mathrm{EF}}=\frac{1}{3}\left(-\frac{\beta_{A B}}{\left|\beta_{E F}\right|\left|\mathrm{D}_{\mathrm{L}}\right| \beta_{K L}}+\frac{1}{\left|\mathrm{D}_{\mathrm{K}}\right|\left|\mathrm{D}_{\mathrm{L}}\right| \beta_{K L}}+\frac{1}{\left|\mathrm{D}_{\mathrm{K}}\right|} \mathbf{K}_{\mathrm{D}_{\mathrm{K}}} N_{\mathrm{EF}}^{\mathrm{K}} \cdot N_{\mathrm{AB}}^{\mathrm{K}}+\frac{1}{\left|\mathrm{D}_{\mathrm{L}}\right|} \mathbf{K}_{\mathrm{D}_{\mathrm{L}}} N_{\mathrm{EF}}^{\mathrm{K}} \cdot N_{\mathrm{EF}}^{\mathrm{K}}+\frac{1}{\left|\mathrm{D}_{\mathrm{L}}\right|} \mathbf{K}_{\mathrm{D}_{\mathrm{L}}} N_{\mathrm{AB}}^{\mathrm{L}} \cdot N_{\mathrm{EF}}^{\mathrm{L}}\right),
\end{aligned}
$$

and the remaining coefficients are determined by symmetry, i.e., $\alpha_{\mathrm{AB} \cdot \mathrm{KL}}=\alpha_{\mathrm{KL} \cdot \mathrm{AB}}$, $\alpha_{\mathrm{EF} \cdot \mathrm{KL}}=\alpha_{\mathrm{KL} \cdot \mathrm{EF}}$, and $\alpha_{\mathrm{EF} \cdot \mathrm{AB}}=\alpha_{\mathrm{AB} \cdot \mathrm{EF}}$. 


\section{Conclusions}

In this work, we discussed how a discontinuous permeability can be treated in the numerical framework offered by the DDFV method. Whenever the discontinuity is across an internal interfaces shared by two control volumes of the primal mesh, two different gradients are considered on the two subdiamonds centered at that interface. Introducing an auxiliary variable at the interface and imposing flux conservation makes it possible to derive a formula for both gradients that is exact for affine functions. Then, a DDFV method can be formulated using a discrete divergence operator to express the flux balance on the overlapping meshes for primal control volumes, vertex control volumes and face-edge control volumes. The numerical experiments in [7] show the effectiveness of the method.

\section{Acknowledgements}

The work of the first two authors was supported by Groupement de Recherche MOMAS. The work of the third author was partially supported by the Italian MIUR through the program PRIN2008.

\section{References}

1. Andreianov, B., Bendahmane, M., Hubert, F.: On 3D DDFV discretization of gradient and divergence operators. Part II. (2011). HAL, http://hal.archives-ouvertes.fr/hal-00567342

2. Andreianov, B., Bendahmane, M., Hubert, F., Krell, S.: On 3D DDFV discretization of gradient and divergence operators. Part I. (2011) HAL, http://hal.archives-ouvertes.fr/hal00355212 .

3. Andreianov, B., Bendahmane, M., Karlsen, K.: A gradient reconstruction formula for finitevolume schemes and discrete duality. FVCA5, Wiley, (2008).

4. Andreianov, B., Hubert, F., Krell, S.: Benchmark 3D: a version of the DDFV scheme with cell/vertex unknowns on general meshes, this volume (2011).

5. Boyer, F., Hubert, F.: Benchmark on anisotropic problems, the DDFV discrete duality finite volumes and m-DDFV schemes. In: R. Eymard, J.M. Hérard (eds.) FVCA5, Wiley, (2008).

6. Coudière, Y., Hubert, F.: A 3D discrete duality finite volume method for nonlinear elliptic equation (2010) HAL, URL: http://hal.archives-ouvertes.fr/hal-00456837/fr.

7. Coudière, Y., Hubert, F., Manzini, G.: Benchmark 3D: CeVeFE-DDFV, a discrete duality scheme with cell/vertex/face+edge unknowns. (this volume) (2011).

8. Coudière, Y., Pierre, C., Rousseau, O., Turpault, R.: A 2D/3D discrete duality finite volume scheme. Application to ECG simulation. International Journal on Finite Volumes (2009) 6(1).

9. Domelevo, K., Omnès, P.: A finite volume method for the laplace equation on almost arbitrary two-dimensional grids. M2AN, Math. Model. Numer. Anal. (2005) 39(6), 1203-1249.

10. Herbin, R., Hubert, F.: Benchmark on discretization schemes for anisotropic diffusion problems on general grids. FVCA5, Wiley, (2008).

11. Hermeline, F.: Approximation of diffusion operators with discontinuous tensor coefficients on distorted meshes. Comp. Meth. Appl. Mech. Eng. (2003) 192(16), 1939-1959.

12. Hermeline, F.: A finite volume method for approximating 3D diffusion operators on general meshes. Journal of computational Physics (2009) 228(16), 5763-5786.

13. Pierre, C.: Modélisation et simulation de l'activité électrique du coeur dans le thorax, analyse numérique et méthodes de volumes finis. Ph.D. thesis, Université de Nantes (2005).

The paper is in final form and no similar paper has been or is being submitted elsewhere. 